\title{
“ESTUDIOS DE GÉNERO”: DOS MUJERES EN PUGNA EN LA CRÍTICA LITERARIA ARGENTINA
}

\begin{abstract}
Marcela Croce*
Resumen: El presente trabajo estudia la carrera de Beatriz Sarlo y Josefina Ludmer, las dos mujeres más representativas en la crítica literaria de la Argentina en las tres últimas décadas del siglo XX. En el caso de Sarlo, su tarea se enfoca en el rastreo de cuestiones sociales y políticas en los textos, para virar progresivamente a los estudios culturales en los años '90. Ludmer, en cambio, comenzó con una perspectiva estructuralista que se fue ajustando aunque siempre privilegiando los aspectos inmanentes y las significaciones múltiples de los textos. Ambas han preferido la crítica de la literatura argentina y proveen un modelo de incorporaciones teóricas y perspectivas críticas, además de dos figuras contrapuesta en lo que atañe a la intervención política de la crítica.
\end{abstract}

\section{BEATRIZ SARLO: LA PERIFERIA COMO ESTRATEGIA CENTRAL}

Beatriz Sarlo (1942) se inició en la crítica literaria hacia fines de la década de 1960, recuperando a Juan María Gutiérrez como fundador del género en la Argentina. Tal elección implicaba

\footnotetext{
* Universidad de Buenos Aires.
} 
dos filiaciones notorias: la más evidente, con la Generación de 1837 -que representó el romanticismo en el país, con su voluntad de dotar a la incipiente nación de una independencia cultural simétrica a la independencia política reclamada desde el 25 de mayo de 1810 -, primer núcleo de intelectuales locales; la otra, correlativa en su empeño, el emprendimiento de la revista Contorno (1953-1959), que elegía ubicarse del lado de "los proscriptos" para pronunciarse contra el peronismo en el poder, antes de plegarse al entusiasmo con la candidatura de Arturo Frondizi en 1958, que se desvaneció a poco de llegar a la presidencia.

Pero sería casi veinte años después de ese comienzo (que Sarlo probablemente perciba a la manera de Said, en los términos reveladores de Begginings según los cuales en la obra inicial se encuentran contenidas las virtualidades que se desplegarán durante la carrera de un autor, ${ }^{1}$ que surgiría la Opus Magna de Sarlo. En las dos décadas intermedias se registran las colaboraciones asiduas para el proyecto cultural del Centro Editor de América Latina - la exitosa creación de Boris Spivacow, cuando el golpe de Estado del general Juan Carlos Onganía en 1966 lo obligó a abandonar la dirección de la editorial universitaria EUDEBA que había fundado unos años antes -, con cierta vocación divulgadora que se advierte en El mundo de Roland Barthes y la antología de los formalistas rusos en un momento en que dichos autores participaban con vehemencia de un secreto de cofradía antes de convertirse en una moda académica, y la férrea voluntad de restituir las condiciones sociales de producción de una obra como se advierte en Literatura / Sociedad (1984) no menos que en la plataforma de lanzamiento provista para el pensamiento de Raymond Williams, tanto en las notas y reportajes contenidos en la revista Punto de Vista (creada y dirigida por la propia Sarlo desde 1978 hasta su reciente cierre

\footnotetext{
${ }^{1}$ SAID. Begginings. Intention and Method.
} 
en 2008) como en ese sucedáneo de Keywords del profesor inglés que se conoce como Conceptos de sociología literaria (1980). ${ }^{2}$

$\mathrm{Y}$ antes de llegar al libro principal, Sarlo haría una incursión en la literatura popular, especializándose en el folletín y el melodrama, aprovechando la circunstancia de que el campo editorial argentino ha sido pródigo en tales producciones. Así lo verifica El imperio de los sentimientos (1984), tras cuyo título de resonancias barthesianas se agrupan argumentos sentimentales, prejuicios burgueses, profesionalización de escritores y vocación de moralización de las clases populares, en un género que Sarlo opta por identificar como "popular" pese a no cumplir las condiciones que exigía Gramsci al respecto, según las cuales para establecer un producto cultural como popular debían corresponder a esta filiación tanto la producción como la circulación y el consumo del mismo. ${ }^{3}$

Con tales antecedentes llega Sarlo a su libro principal, Una modernidad periférica: Buenos Aires 1920 y 1930, ${ }^{4}$ que comienza con un reconocimiento de deudas intelectuales donde Carl Schorske y Marshall Berman se destacan en una "biblioteca mental" integrada previsiblemente por Barthes, Benjamin, Williams y otros autores ya canónicos. En la búsqueda de método que encara -consciente de que la construcción de un objeto novedoso como "la vanguardia" en la Argentina reclama un abordaje original-, se produce un desplazamiento que conduce de "no se me ocurre nada" (lo que justifica la apelación a los grandes nombres que desgrana) a "se me ocurren cosas nunca dichas".

\footnotetext{
${ }^{2}$ Tanto este libro como Literatura / Sociedad fueron realizados en colaboración con Carlos Altamirano, con quien también organizaría los textos de Ensayos argentinos. De Sarmiento a la vanguardia (1983).

${ }^{3}$ GRAMSCI. Los intelectuales y la organización de la cultura.

${ }^{4}$ SARLO. La máquina cultural. Maestras, traductores y vanguardistas. En adelante, los números de página corresponden a esta edición.

${ }^{5}$ SARLO. Una modernidad periférica. Buenos Aires 1920 y 1930, p. 8.
} 
La experiencia crítica se superpone a la experiencia urbana para caracterizar al intelectual moderno como quien percibe los rasgos de la ciudad y se detiene en sus manifestaciones y representaciones.

La construcción de la originalidad resulta contradictoria, ya que se produce en el cruce de la biblioteca mental heterogénea y la cultura de mezcla que campea en la Argentina. La originalidad asentada en este rasgo desencadena una vacilación en torno al género discursivo del libro, que oscila entre "el régimen de la historia cultural, de la intelectual bistory, de la historia de los intelectuales o de las ideas". ${ }^{6}$ Claro que para abundar en esas variedades, parece necesario renunciar a ciertas categorías marxistas que en la época de $\operatorname{Los}_{\text {Libros }}^{7}$ Sarlo había manejado con soltura. Las "clases" son reemplazadas por las "capas" e incuso por los "sectores", deteniéndose en los ilustrados que consumen revistas. Éstas son concebidas como tomas de posición (en términos que adhieren a la definición williamsiana de las "formaciones"), y desde allí conviene leer los agradecimientos que la autora depara a los redactores de Punto de Vista y La Ciudad Futura, en la época en que ambas publicaciones integraban el arco de difusión del Club de Cultura Socialista en el que Sarlo militaba.

Maniquea para eludir la dialéctica, Sarlo prefiere la vanguardia del grupo de Florida con su condensación de técnica y estética antes que el arte social que predicaba el grupo de Boedo.

\footnotetext{
${ }^{6}$ SARLO. Una modernidad periférica. Buenos Aires 1920 y 1930, p. 9.

${ }^{7}$ Los Libros fue una revista creada en 1969, al principio bajo la dirección de Héctor Schmucler y el respaldo de Editorial Galerna. Aunque inicialmente procuraba dar a conocer el estructuralismo francés y las novedades en el campo de las Humanidades y las Ciencias Sociales, fue virando hacia la política por las urgencias del momento. Así, en 1971 ya se había convertido en una mixtura de cultura y política, para tornarse en 1973 una publicación francamente política. Schmucler pasará a compartir la dirección con un consejo que, hacia 1975, será reemplazado por la orientación de Sarlo, Altamirano y Ricardo Piglia, antes de clausurarse en septiembre de ese mismo año en medio de la crisis política desencadenada por la sucesión del general Perón.
} 
La masividad y la democratización son correlativas; la revolución, tanto en arte como en política, apela a fundamentos ajenos al mercantilismo. En realidad, lo que funciona en este punto es un prejuicio abonado por la crítica de la cultura popular en la Argentina, cuyo sustento en generalizaciones excesivas la conduce a sofismas: así, si todo lo masivo es popular y todo lo masivo es democrático, se infiere que todo lo popular es democrático. Ésa fue la convicción que orientó los textos más significativos de Aníbal Ford, Jorge Rivera y Eduardo Romano desde los años ' 70.

Sarlo se ocupará más que de una historia social de la literatura, de una tipología de intelectuales a partir de sus intervenciones textuales y políticas. La situación del intelectual se establece sobre la respuesta a las preguntas que organizan los debates de la época. Sarlo parece inclinarse aquí por una historia de las subjetividades más próxima a la historia de la vida privada fomentada por la Escuela de los Anales francesa que a la sociología de la literatura, la que se debilita con el recurso a presuntas categorías de dudosa definición como la de gusto y, más estrictamente, la descalificación reservada al "mal gusto". ${ }^{8}$

Sin embargo, siguen resonando ciertos conceptos de sociología literaria: la eventual correspondencia entre situación social y elección estética; la duplicación de la relación ciudad/ campo - de raigambre en Williams - en tecnología y naturaleza; la insistencia en los ideologemas de estirpe jamesoniana. Podría proponer que en el cap. II Sarlo pone en serie sus producciones, las previas y las venideras, como si trazara un plan de su obra a partir de las inquietudes enunciadas: los textos de Historia universal de la infamia (1935) de Borges pueden leerse como

\footnotetext{
${ }^{8}$ La fascinación con el urbanismo (aunque sea periférico, o tal vez justamente por eso) lleva a Sarlo a excederse en la prejuiciosa correlación entre provincianismo y mal gusto: "Maestra de provincia, Alfonsina [Storni] no puede, en estos primeros años, ser otra cosa que una poetisa de mal gusto." (SARLO. Una modernidad periférica. Buenos Aires 1920 y 1930, p. 78).
} 
contrapartida de los folletines organizados en El imperio de los sentimientos; ${ }^{9}$ las orillas conducen a Borges: un escritor en las orillas (1995); el tópico de La imaginación técnica (1992) se perfila en el axioma de que "la técnica es la literatura de los humildes y una vía hacia el éxito que puede prescindir de la universidad o de la escuela media" (p. 57). E incluso la referencia a la distribución desigual de la cultura, en La máquina cultural (1998) se convertirá en un pronunciamiento velado por el antidemocratismo.

La presencia de Pierre Bourdieu como referencia constante exige una definición estricta del "campo intelectual" y obliga a establecer los modos de autonomía de la esfera estética en el contexto argentino de los '20 y '30: "la consagración se produce entre pares" (p. 108). Pero más que la aplicación directa del modelo de Bourdieu es el ajuste argentino al análisis desarrollado por Julio Ramos el que domina en este segmento, donde la autonomización del campo estético se verifica en la ruptura respecto de la propuesta alambicada del modernismo.

De allí la preferencia por Raúl González Tunón, que responde a su significación renovadora tanto en el orden político como en el literario, algo evidente en el poema "Historia de veinte años" en cuyo recurso al romance, tal como Sarlo señala a partir de la caracterización retórica que traza Hayden White (1992), la clase pasa a ser protagonista en la sucesión de versos, mientras el

\footnotetext{
${ }^{9}$ Más aun: la novela sentimental es una 'lectura fácil' por su codificación estética y su moralización, del mismo modo que la poesía de Alfonsina resulta "cursi". Incluso "Alfonsina corrige algunos tópicos de la literatura erótica" (SARLO. Una modernidad periférica. Buenos Aires 1920 y 1930, p. 82), pero ¿cómo se pueden "corregir" los tópicos sin que pierdan su carácter de tales? Es posible reponer a partir de tales calificaciones una dualidad entre lo fácil y lo difícil: del primer lado se ubica lo bajo y la hipercodificación del género; en el otro extremo se sitúa lo alto y la innovación de la vanguardia. Esas dualidades no dialectizables limitan el método crítico, cuyos juicios de valor no se construyen en el proceso crítico sino que se instalan como prejuicios de partida.
} 
individuo pierde ese espacio que se le reservaba en el arte burgués. La literatura concebida como producción de ideología afecta también a los "marginales" a quienes concede el cap. VII. Se trata de quienes escriben en los alrededores del grupo de Boedo: puede ser Enrique González Tuñón - cuya dedicatoria de Tangos a "San Juan de Dios Filiberto" duplica la de las Misas berejes de Carriego a "San Juan Moreira", detalle que Sarlo saltea para no sugerir semejanza alguna entre la operación boedista y la borgeana -, Nicolás Olivari - en cuya poesía se asiste al pasaje de la fe colectiva en la revolución a la desazón individual de la miseria -, Lorenzo Stanchina - a quien imagina empecinado émulo de Arlt - o Leónidas Barletta - sobre cuyos personajes de Royal Circo justifica que viajen en un vagón de segunda porque "son vidas de segunda clase" ${ }^{10}$ (SARLO, 1988, p. 198). Resulta sintomático que el uso de la categoría de "clase" sea un auxilio cuando opta por la descalificación. ${ }^{11}$

\section{ENSAYO DE CRÍTICA CULTURAL}

A partir de 1994 Sarlo expande el terreno de la crítica sociológica de la literatura para ingresar en la crítica cultural. Su primer ejercicio es Escenas de la vida posmoderna. Intelectuales, arte y videocultura en la Argentina. Un tópico del libro de 1988 equipara la "vida posmoderna" con la "modernidad periférica", pero ya no se recorta en las espacializaciones previsibles sino que

\footnotetext{
${ }^{10}$ SARLO. Escenas de la vida posmoderna, p. 10.

${ }^{11}$ La admisión de que el "gusto" no es una definición estética se expone en la relación analógica que reciben "clase" y "gusto": "Castelnuovo es alguien que sus contemporáneos de las corrientes renovadoras consideraban un escritor 'sin gusto', con todo lo social que encierra este juicio (...) Tiene una noción plebeya de la sintaxis narrativa y siempre dice lo que un escritor de mejor oficio elude. Su voyeurismo es insaciable" (SARLO. Una modernidad periférica. Buenos Aires 1920 y 1930, p. 201).
} 
establece sobre ellas antes que las figuras de intelectual reales, las posibles o deseables. La propia Sarlo se coloca como intelectual faro que establece los temas sobre los cuales discutir, reduciendo la dimensión política que convoca a actuar: "No son preguntas de qué hacer sino del cómo armar una perspectiva para ver". ${ }^{12}$ El recorrido del libro aborda tres espacios: "el de los medios audiovisuales y su mercado; el de las antes denominadas culturas populares; el del arte y la cultura 'culta'". ${ }^{13}$ El presupuesto para la crítica de los medios, acaso por la decisión de abordaje formalista (la televisidad es el sucedáneo de la literaturidad), cae en el mismo error que arrastraron los formalistas rusos de creer que la producción y la recepción son homogéneas y que, por lo tanto, los efectos buscados a nivel constructivo son los que se generan en la recepción. Las preguntas que organizan esta cuestión de método oscilan entre el intelectual populista que se desdeña y el intelectual académico, universitario, que se procura matizar en su rol de "mandarín".

Pese al voluntarismo analítico, hay conflictos que Sarlo no logra superar. El shopping desideologizado al resolverse en pura descripción aparece definido desde categorías que le resultan no solamente ajenas sino por añadidura refractarias: sumar la negatividad frankfurtiana a la desterritorialización deleuziana resulta un despliegue innecesario. La comparación entre historia y shopping queda deslegitimada por la supresión de la historia que se mantiene en la mayoría de los capítulos, y la definición de lo público es tan tortuosa que termina en el absurdo.

El mercado es paradójico y desde allí se lo critica, ignorando la lógica que Marx repuso sobre sus condiciones. Tal vez porque resulta más simple indagar paradojas de la vida posmoderna que entrometerse con las contradicciones de los intelectuales. La

\footnotetext{
${ }^{12}$ SARLO. Escenas de la vida posmoderna, p. 10. Los números de página corresponden a esta edición.

${ }^{13}$ SARLO. Escenas de la vida posmoderna, p.10-11.
} 
paradoja pareciera ser algo que sobreviene; la contradicción, por el contrario, es una construcción, un acto responsable. La incipiente crítica cultural se modela sobre la práctica de la crítica literaria y se advierte en la lectura que opera desde los géneros, concurrente con un estilo crítico de impersonalidad hispanohablante ("gasolinera"), además de una sustracción de los juicios de valor en favor de enunciados de orden normativo ("Primera ley...") o directamente banales ("El zapping suscita una serie de cuestiones interesantes". ${ }^{14}$

La televisión plantea un democratismo práctico: "hay un solo modo de aprender televisión: viéndola. Y es preciso convenir que este aprendizaje es barato, antielitista e igualador". ${ }^{15} \mathrm{La}$ democracia queda asociada así a lo bajo, lo simple y lo negativo; ${ }^{16}$ incluso incurre en la desestimación del público al que uniformiza en todo excepto en la dimensión económica. Sarlo cree que la ampliación del público implica el reconocimiento de un género y en este punto se maneja con argumentos de mercado: en la pantalla se incorpora el folletín que las élites intelectuales despreciaron, pero ese argumento sociológico inmediatamente se aplaca con uno formalista que sostiene que los problemas estéticos son problemas de producción, de "artificio". ${ }^{17} \mathrm{Si} \mathrm{los}$ intelectuales "altos" oscilan entre el "elitismo pasatista" y el "vanguardismo

\footnotetext{
${ }^{14}$ SARLO. Escenas de la vida posmoderna, p. 64.

${ }^{15}$ SARLO. Escenas de la vida posmoderna, p. 98.

${ }^{16}$ El juicio negativo sobre la democracia se enuncia sobre una desconfianza similar a la que le merece el relativismo: "El relativismo es como la democracia: una vez que son escuchadas sus promesas, todo cae ante el ímpetu nivelador e igualitario de su impulso" (SARLO. Escenas de la vida posmoderna, p. 157). La idea de que la democracia resulta una amenaza para el arte se reitera en el libro: "la modernidad, cuando es sensible a la democracia, es pedagógica; el gusto de las mayorías debe ser educado, en la medida en que no hay espontaneidad cultural que asegure el juicio en materias estéticas. Lo mismo podría decirse de las más diversas variantes de pedagogía política" (SARLO. Escenas de la vida posmoderna, p. 162).

${ }^{17}$ SARLO. Escenas de la vida posmoderna, p. 104.
} 
pedagógico"18 en torno a la televisión, el intelectual orgánico que intenta diseñar Sarlo se aparta de ambas alternativas, del mismo modo que excluye la compleja dicotomía de Umberto Eco entre "apocalípticos e integrados" -que ella traduce en "legitimistas" y "asalariados"-, pero defiende a la televisión por la cooptación que cumple y de la cual es incapaz el sistema escolar.

A lo largo de todo el libro, Sarlo anuncia el rol de cronista de superficialidades que asumirá ya entrado el siglo XXI, al desempeñarse en la revista dominical Viva del diario Clarín: el texto es una extensa disquisición menos sobre los medios y el mercado que sobre el "interés general" como situación esquiva. La relación de los intelectuales con el mercado es un punto que siempre queda pendiente, mientras la vanguardia nuclea todas las positividades que admite Sarlo.

\section{BORGES, SIEMPRE BORGES}

Habrá que esperar a Borges, un escritor en las orillas (1995) para asistir al momento en que el intelectual se reconoce catedrático. El ritmo y el tono de la clase magistral impregnan el libro - abusando de las bastardillas para marcar diferencias tonales-que, resultado de la estadía de Sarlo en Oxford ocupando la Simón Bolívar Chair, se expande en Weltliteratur para restringirla inmediatamente a "la corriente universalista de la literatura occidental", ${ }^{19}$ lo que de paso introduce la primera de las múltiples metáforas desdichadas del texto, desde "la fama custodia su obra como un espectro inmóvil" ${ }^{20}$ hasta "la luz perfecta de sus textos". ${ }^{21}$

\footnotetext{
${ }^{18}$ SARLO. Escenas de la vida posmoderna, p. 87.

19 SARLO. Borges, un escritor en las orillas, p. 8. Los números de página corresponden a esta edición, traducción del original inglés Jorge Luis Borges, a writer on the edge (1993).

${ }^{20}$ SARLO. Borges, un escritor en las orillas, p. 18.

${ }^{21}$ SARLO. Borges, un escritor en las orillas, p. 204.
} 
O, ya en el orden de la antonomasia, "grande entre los grandes", ${ }^{22}$ sin desdeñar la intersección de antonomasia y tautología que certifica cierta incapacidad crítica ante la fascinación con el objeto ("después de estos cuentos [los de Historia universal de la infamia], Borges es ya definitivamente Borges. ${ }^{23}$ Tal vez la razón del estilo sea que la propia profesora se siente "una provinciana ingenua" frente a los esplendores oxonienses; abundando en la serie iniciada por Alberto Gerchunoff con "el hombre que habló en la Sorbona", Sarlo es "la mujer que habló en Oxford".

Insistiendo en lo periférico como categoría cultural que ella misma estaría representando en su situación inglesa, la pregunta que organiza el libro es "¿cómo puede escribirse literatura en una nación culturalmente periférica?”, ${ }^{24}$ lo que señala una concepción elitista que repercute en la voluntad de leer a Borges en clave borgeana: "al mismo tiempo cosmopolita y nacional", ${ }^{25}$ traidor y héroe. La ciudad de las orillas de Borges es la primera caracterización de una sucesión que integra la ciudad tecnologizada de Arlt y la ciudad de cámara Kodak de Girondo como variantes posibles de la mirada vanguardista sobre el espacio urbano. Las "orillas" reclaman una extensa explicación en función de las limitaciones - que Sarlo, cortésmente, ofrece como multiplicidaddel término inglés "edge": "margen, filo, límite, costa, playa", ${ }^{26}$ aunque es evidente que las últimas posibilidades no se manifiestan nunca en los textos borgeanos.

Las orillas pretenden resolver un conflicto que opera en dos planos, porque si el problema está entre el nacionalismo y el realismo, atañe simultáneamente a la política y la literatura y obliga a politizar las orillas, circunstancia que Sarlo elude situándolas

\footnotetext{
${ }^{22}$ SARLO. Borges, un escritor en las orillas, p. 9.

${ }^{23}$ SARLO. Borges, un escritor en las orillas, p. 118.

${ }^{24}$ SARLO. Borges, un escritor en las orillas, p. 12.

${ }^{25}$ SARLO. Escenas de la vida posmoderna, p. 14.

${ }^{26}$ SARLO. Borges, un escritor en las orillas, p. 52.
} 
en la zona vanguardista de la pura polémica cultural. La despolitización del margen lo libera de un barniz "popular" que invocaría al Gramsci al que Sarlo se resiste en el contexto de Oxford, porque la izquierda intelectual en Inglaterra equivale a adherir a New Left Review. ${ }^{27}$

\section{EVOCACIONES}

El último libro de Sarlo que abordaré aquí es La máquina cultural. Maestras, traductores y vanguardistas (1998), ${ }^{28}$ que se abre con un agradecimiento por la beca Guggenheim. El conjunto consta de tres grandes divisiones, en el marco de un ejercicio de sociología de la cultura que impregna tanto lo metodológico como la convicción sobre el normalismo como promesa de ascenso social para las clases bajas inmigratorias. El primer segmento trastorna el modelo de Bourdieu para quien el intelectual es la "fracción dominada de la clase dominante", evitando precisar a la maestra como ejecutora de consignas ajenas sobre las que a lo sumo puede efectuar una modificación.

En el capítulo dedicado a Victoria Ocampo, la guía de Bourdieu es reemplazada por la de Lucien Goldmann, autor cuya lectura había dejado de ser habitual en los años '90. La recuperación de algunos temas de Le Dieu caché, el extenso estudio que le dedica a Jean Racine, alude a la distinción entre nobleza de toga y nobleza de renta para situar a la fundadora de Sur como una especie de "vanguardista" en términos musicales -ser vanguardista para Sarlo es tener un valor estético-, ya que en el literario es bastante más renuente a esa calificación.

\footnotetext{
${ }^{27}$ El propio Terry Eagleton, miembro central del izquierdismo inglés, creará una boutade en su libro sobre Walter Benjamin para ironizar sobre la operación del grupo: "más que marxistas ingleses, son ingleses marxistas".

${ }^{28}$ SARLO. La máquina cultural. Maestras, traductores y vanguardistas. Los números de página corresponden a esta edición.
} 
En Victoria la educación sentimental resulta desplazada por la formación cultural que la impulsa a la traducción al tomar conciencia de la condición periférica de su origen. Y aquí se expone de manera más clara la definición que obsesiona a Sarlo: un "intelectual periférico" es aquel que debe leer las grandes obras en traducción y que sólo alcanza reconocimiento cuando es traducido a una lengua "central". La relación con lo central se define en Victoria Ocampo no sólo en la traducción sino inicialmente en la cita. El énfasis en el concepto de "máquina" confía en que la cultura participa de tal condición, aunque menos dedicada a la producción que a la transformación.

El último capítulo del libro plantea la oposición cerrada entre vanguardia estética y vanguardia política en el campo cinematográfico. Cuando ambas se cruzaron, "todo terminó en una batalla campal provocada por un malentendido gigantesco". ${ }^{29}$ Sin embargo, la vanguardia estética será atenuada en "experimentación", mientras la política resulta degradada - en el sistema de valores que maneja la crítica- por su voluntad de representación realista. El prejuicio, elevado a categoría, instala a las vanguardias como fenómenos centrales que pueden "exportarse" a la periferia - en este caso, el interior del país- pero no pueden producirse en ella. Y si Sarlo condena también "el costado fuertemente verbalista de la izquierda revolucionaria" sesentista, ${ }^{30}$ es porque traza un trayecto entre el voluntarismo de las izquierdas de los '20 y '30 que analizaba en Una modernidad periférica hasta las izquierdas más radicalizadas de los ' 60 y '70 de las que se ocupa sólo en aspectos discursivos o fílmicos, esquivando sus actuaciones concretas. ${ }^{31} \mathrm{El}$

\footnotetext{
${ }^{29}$ SARLO. La máquina cultural. Maestras, traductores y vanguardistas.

${ }^{30}$ SARLO. La máquina cultural. Maestras, traductores y vanguardistas, p. 239.

${ }^{31}$ Incluso insiste en descalificar al cine de la resistencia peronista cuando señala que "una política revolucionaria necesita un arte estéticamente revolucionario y no un comentario artístico subordinado" (SARLO. La máquina cultural. Maestras, traductores y vanguardistas, p. 288).
} 
cierre de La máquina cultural se pronuncia por la "alta cultura" representada por el cruce de los tonos borgeanos y las imaginerías de Henry James cuya "figura en el tapiz" se impone buscar en una reconstrucción deliberadamente fragmentaria, empecinadamente autojustificatoria, voluntariamente vanguardista en dirección única: "Cada episodio debió encontrar su tono y cuando apareció el tono tuve la impresión de que empezaba a comprender la historia a través del dibujo que tomaba el relato." 32

\section{JOSEFINA LUDMER: LA FE EN UN MODELO}

Iris Josefina Ludmer (1939) representa un apartamiento notorio respecto de la línea de crítica social y cultural practicada por Sarlo. En primer término, su fascinación con el estructuralismo redunda en un texto plagado de esquemas, genealogías y levistraussianas estructuras elementales del parentesco, recursos desplegados en la lectura de uno de los clásicos del boom latinoamericano. Así, Cien años de soledad. Una interpretación (1972) sale con el sello de la editorial Tiempo Contemporáneo que se encargaba de difundir las mayores novedades de procedencia francesa, tanto la monumental biografía de Sartre $E l$ idiota de la familia (traducida por Sarlo y Altamirano) como la revista Communications que daba a conocer los principales nombres de la intelectualidad parisina: Barthes, Christian Metz, A. J. Greimas, Gérard Genette y los búlgaros Tzvetan Todorov y Julia Kristeva. Sobre esta última figura, la de la mujer empeñada en matematizar la teoría literaria, Ludmer diseñará una de sus intervenciones más significativas, la que una década y media después de su libro inicial se expande en gráficos de Cantor $^{33}$ y

\footnotetext{
${ }^{32}$ SARLO. La máquina cultural. Maestras, traductores y vanguardistas, p. 291.

${ }^{33}$ El esquema de George Cantor se ajusta en este caso a la convicción de que la gauchesca traza una "red en diagonal", que responde al modelo shklovskiano de descendencia según el cual la herencia literaria corre de tío a sobrino, y no de padre a hijo.
} 
especulaciones sobre el lenguaje poético, demasiado alambicadas para abordar la poesía popular del género gauchesco.

El prólogo de Cien años de soledad. Una interpretación es un manifiesto que apunta contra la crítica sociológica a la manera de Sarlo, no menos que contra el impresionismo y cualquier historicidad que no sea interna a la práctica literaria. Sin explicitarse, la palabra "inmanencia" sobrevuela el texto y provee un apoyo a las dualidades no dialectizables que se irán acumulando en los capítulos a manera de división de funciones. Desde esta perspectiva, el esquema presenta una realidad mientras el mito condensa una ideología; el sintagma y el paradigma se articulan en la lectura del árbol familiar; la sintaxis organiza toda la narración planteando conjunciones y disyunciones y la operación de fragmentación que arraiga en el procedimiento de las lexías establecido en $S / Z$ insiste en dejar huellas de la fascinación barthesiana: si en el manifiesto inicial resuena Crítica y verdad y en el orden metodológico se destaca $S / Z$, la convicción con que proclama la desaparición de la figura autoral participa de una fe empedrada de principios y presupuestos críticos que se conjugan con las lecturas múltiples y la significación inacabada, cuya correspondencia en el orden lingüístico la provee la semiosis ilimitada de Charles S. Peirce.

Sin embargo, esta labor modernizada en conceptualización, no vacila ante las categorías clásicas como drama, intriga y fatum. La complacencia crítica decide leer al texto tal como éste parece solicitarlo; de ese modo, el relato prescriptivo resulta correlativo de la crítica normativa y codificadora que descansa en la presunta aptitud del sistema para garantizar un conjunto de enunciados que se sostienen en la dependencia mutua. Los mismos vicios estructuralistas de Cien años... se imponen en Onetti, los procesos de construcción del relato (1977), cuyo título es mucho más preciso que el anterior en su raigambre formal-estructuralista, al prescindir de las ambigüedades que arrastra la noción de "interpretación”. Lo que en el primer libro era manifiesto, definición 
desafiante, aquí se anquilosa en dogma que rechaza parejamente el idealismo como tendencia vanguardista y el "populismo naturalista" ${ }^{34}$ que se admite como su contrapartida. ${ }^{35}$ Y si en Cien años... la adhesión a Barthes se ubicaba en la contemporaneidad inmediata, ahora son los conceptos de El grado cero de la escritura (1953) los que se desarrollan. Hacia atrás y hacia adelante, Onetti... funciona como bisagra: mientras el abuso de las comillas recuerda la sobresaturación del primer libro, las "largas cadenas reflexivas"36 flexionan hacia El género gauchesco; mientras los textos de Onetti son remitidos a sus propios antecedentes, la obsesión por "el espacio fundante" 37 anticipa el libro de 1988. El tironeo dramatiza las condiciones de la literatura: "el engendramiento y el corte se ligan en una figura contradictoria, sello de la literatura" ${ }^{38}$ La crítica de Ludmer se especializa en el rastreo de tópicos teóricos; la teoría es, fundamentalmente, un modo de ejercer control sobre la creación literaria, ya sea proveyendo los elementos constructivos para su organización, ya sea respaldando los juicios críticos que suceden a su ejecución.

El recorrido de Onetti... convoca un consorcio de modelos, desde la hermenéutica ("los sentidos del nombre Díaz Grey") hasta la semiótica kristeviana ("un procedimiento o mecanismo estructural debe encontrarse paragramáticamente en todos los niveles de un texto", ${ }^{39}$ sin desdeñar un pasaje por la estilística en que indaga "el proceso de producción del 'estilo' de Onetti". ${ }^{40}$ pero la reunión de estructuralismo y estilística previsiblemente

\footnotetext{
${ }^{34}$ LUDMER Onetti, los proceso de construcción del relato, p. 12

${ }^{35}$ LUDMER. Onetti, los proceso de construcción del relato. Los números de página corresponden a esta edición.

${ }^{36}$ LUDMER. Onetti, los proceso de construcción del relato, p. 11.

${ }^{37}$ LUDMER. Onetti, los proceso de construcción del relato, p. 11.

${ }^{38}$ LUDMER. Onetti, los proceso de construcción del relato, p. 19.

${ }^{39}$ LUDMER. Onetti, los proceso de construcción del relato, p. 71.

${ }^{40}$ LUDMER. Onetti, los proceso de construcción del relato, p. 83.
} 
concurre en desmedro de esta última, relegando el estilo a la función de síntoma de la estructura. Atenta a la renovación lingüística, Ludmer pretende articular el estructuralismo francés con el transformacionalismo chomskyano al sostener que "la clave [de un texto] está en la transformación del sentido". ${ }^{41}$ Lo referencial y contextual queda relegado a nota al pie mientras el texto principal prolifera en conceptos y esquemas, abunda en barras y dualidades e insiste en supresión de la ideología completando la teoría chomskyana con la benvenisteana: "se sabe que es en la sintaxis donde se define el lugar del sujeto". ${ }^{42}$

La autonomía de la crítica es inmediatamente verificable en los trabajos de Ludmer, para quien la distancia entre ficción y teoría consiste en un cambio de registro, lo que certifica que los textos participan de un discurso único. Allí donde Barthes establecía el fascismo de la lengua que no permite enunciar lo que el sujeto desea sino apenas aquello que las virtualidades del lenguaje autorizan, Ludmer instala el imperialismo de la escritura, evitando cualquier precisión en la confianza extrema en su guía crítica, para quien "escribir" es un verbo intransitivo.

\section{LA PATRIA ES UNA LENGUA}

Las dualidades siguen siendo la marca de la crítica de Ludmer, más aun que las pretendidas plurisignificaciones. A poco de iniciado El género gauchesco. Un tratado sobre la patria (1988), se instala la más productiva: "Desafío y lamento, los tonos de la patria", antes de expandirse en el binomio cantor (popular) / (George) Cantor, o bien en Borges / Kafka en el sugestivo parágrafo "Borges ante la ley", además de la alternancia entre don y uso que organiza el índice. El cierre del libro vuelve sobre este punto:

\footnotetext{
${ }^{41}$ LUDMER. Onetti, los proceso de construcción del relato, p. 90.

${ }^{42}$ LUDMER. Onetti, los proceso de construcción del relato, p. 133.
} 
si la relación entre "uso" y "don" «3 convoca a los términos legales (donación y usufructo), la referencia puntual a una serie de becas entre las que sobresale la Guggenheim repone otro "don": la graciosa concesión de un padrino adinerado que permite la investigación de "pensar en el género en mi patria".

Los modelos de análisis literario son desplazados por los sistemas lógicos: así, mientras la parcelación y numeración del índice pretende continuar la del Tractatus Logico-Philosophicus de Ludwig Wttgenstein, es evidente el semantismo de Frege en la categorización escogida, no menos que el pragmatismo de John Austin entre cuyos fundamentos se encuentran las especulaciones wittgensteinianas. Pero así como en la fórmula "uso letrado de la cultura popular" con que se define la gauchesca se advierte una consulta lingüística, el libro prescinde por completo del antecedente insoslayable que representa la indagación de Ángel Rama en Los gauchipolíticos rioplatenses (1976) y prefiere seguir "la estela de Gramsci" abarrotando las referencias con teóricos italianos cuya contribución a la literatura popular no los habilita necesariamente a ajustarse a la gauchesca. Acaso tal preferencia se ampare en la forma de "tratado" conferida al libro, contrapartida exacta de lo que en su siguiente libro será la elección del "manual", en un recorrido que conduce de lo popular canonizado (tratado gauchesco) a lo popular marginalizado (manual delictivo) y que parece reproducir la ilusión y la paradoja de la crítica en la superposición de la ilusión referencial (literaria) y el fantasma de la ilusión de transparencia. ${ }^{44}$

Una de las marcas distintivas del discurso de Ludmer es la elaboración de categorías que no responden a la definición

\footnotetext{
${ }^{43}$ Que implica un evidente desvío respecto de la relación entre lenguaje denotativo y metalenguaje, entre "uso" y "mención" en la conceptualización que consta en Sobre sentido y referencia de Gottlob Frege.

${ }_{44}^{44}$ Todas las citas corresponden a LUDMER. El género gauchesco. Un tratado sobre la patria, p. 14-15.
} 
clásica que ostentan. Así, por ejemplo, la epistemología no es la filosofía de la ciencia sino una categoría asociada a la experiencia directa -es el conocimiento que se desprende a partir del uso de un objeto -; la delincuencia es entendida como producción (flexionando hacia el libro siguiente, El cuerpo del delito, en que la productividad de las prácticas ilegales resulta respaldada por la cita de Marx); la gauchesca es un género de adoctrinamiento en tanto centraliza la noción de patria - lo que explica su inclusión en el canon escolar. A su vez, la crítica de Ludmer se propone como normativa, cada vez más tendiente a condensarse en fórmulas y reglas: de este modo, las reglas del género gauchesco (la reproducción escrita de la oralidad y la construcción del espacio oral) se superponen a la fórmula dominante del tratado: "uso letrado de la cultura popular". El género resultaría en consecuencia la inserción de la serie lógica en el corpus literario, y en ese marco se produce la guerra de definiciones que se disputan la caracterización más ajustada de la "patria".

A la enunciación formular que convoca en el texto los anillos de Einstein, el modelo diagonal de Cantor y el aut-aut kierkegaardiano que se radicaliza en el gaucho, se le superpone una serie literaria que arranca en la gauchesca, se extiende al tango y culmina en el grotesco, donde el desafío y el lamento se erigen en línea rectora de "hombres rivales o sexos rivales" (el tango) o de "pacto contradictorio" ${ }^{45}$ con los inmigrantes (el grotesco). ${ }^{46} \mathrm{Y}$ ya se tiende la línea que vincula, en el mismo año 1988 en que se editan El género gauchesco de Ludmer y Una modernidad periférica de Sarlo, a las dos críticas más representativas de finales

\footnotetext{
${ }^{45}$ LUDMER. El género gauchesco. Un tratado sobre la patria, p. 219.

${ }^{46}$ Del grotesco como tragicómico podría desprenderse la equivalencia entre tres parágrafos del Capítulo tercero y tres formas dramáticas: si "En el paraíso del infierno", donde se aborda la localización del espectador del Fausto criollo, transita la comedia, el título mismo de "El Fausto argentino" convoca la tragedia y "Un pastiche de crítica literaria" incurre en la farsa.
} 
del siglo XX en la Argentina, cuando la primera lee en Evaristo Carriego "las marcas históricas de la vanguardia y del deseo de modernidad de Borges" ${ }^{47}$ que indaga la segunda.

El género gauchesco cesa con la consolidación del Estado nacional en 1880, tras haber recorrido la serie de la filosofía política que se abre con el protoliberalismo rousseauniano en Bartolomé Hidalgo, continúa en el liberalismo de Ascasubi y se cierra con el ultraliberalismo que acarrea la simpatía masónica adjudicada a Hernández. En el medio, como una presencia constante, se despliega Sarmiento, cuya "vida ejemplar" diseñada en Recuerdos de Provincia parece ser el modelo invertido que opera en la vida del pícaro que corresponde al personaje de Picardía. ${ }^{48}$

El último libro unitario de Ludmer se titula El cuerpo del delito (1999) y viene anunciado por los textos previos, en especial por el de la gauchesca que abunda en marginales y fuera de la ley. Al tiempo que un enunciado marxista se convierte en línea rectora del ensayo, la teoría es admitida en su condición ficcional ("la teoría-ficción de Darwin de la horda primitiva”“99 $)$. En continuidad con El género gauchesco, Ludmer define al lector argentino como destinatario deseable del texto que prosigue la obsesión con lo nacional ya desarrollada anteriormente (argentinizar equivale a incorporar los géneros europeos al país) y parece retomar allí donde se cerraba el texto de 1988 cuando caracteriza a la Generación del 80 como "coalición cultural y literaria [...], una coalición estatal, quizá la primera". ${ }^{50}$ La literatura antirrosista que es la gauchesca se le añade ahora la literatura liberal que se pliega

\footnotetext{
${ }^{47}$ LUDMER. El género gauchesco. Un tratado sobre la patria, p. 226.

${ }^{48}$ Cf. ALTAMIRANO; SARLO. Una vida ejemplar: la estrategia de Recuerdos de Provincia.

${ }^{49}$ Los números de página corresponden a LUDMER. El cuerpo del delito. Un manual, p. 13.

${ }^{50}$ LUDMER. El cuerpo del delito. Un manual, p. 47.
} 
a la construcción del Estado - de Fausto se pasa a En la sangre. ${ }^{51}$ Correlativamente, a los enunciados reglamentaristas y legales que campean en $E l$ género gauchesco y se condensan en fórmulas, le suceden en este recorrido epistemológico y discursivo trazado por la crítica los axiomas, de modo que el Manual se va precisando como colección de enunciados apodícticos.

En el orden de las elecciones de objeto, el diseño del corpus va exponiendo su condición de sostén de series, de modo que los géneros y los tópicos definen series nacionales: "se instalan 'cuentos' que forman series, cadenas, familias, genealogías, y que nos llevan al futuro": cuentos de exámenes, simuladores, locos y otros personajes del acervo positivista que tanto influyó en la conformación del Estado nacional. ${ }^{52}$ En el armado de series se revela el trazado del manual, proclamado "un trabajo escolar' para mis queridos maestros del grupo Contorno" 53 entre quienes destaca al que fuera su marido, Ramón Alcalde. El puente entre los capítulos del libro se pone de relieve en las notas antes que en el cuerpo textual; en ellas se sostiene el cuerpo del delito, sobre la práctica del robo de fuentes y la recuperación de citas. Y también en ellas se establecen las polémicas: es allí donde Ludmer convoca la referencia a Sarlo (a través de La imaginación técnica. Sueños modernos de la cultura argentina (1992). Buenos Aires, Nueva Visión), aunque no como apoyo a su trabajo sino para subrayar las limitaciones que le encuentra.

Acaso el capítulo más significativo de El cuerpo del delito es el que Ludmer le dedica a Juan Moreira. Como personaje, es

\footnotetext{
${ }^{51} \mathrm{Si}$ en el texto de del Campo el teatro Colón es la sede de la clase alta en la cual se infiltra un gaucho ridículo, "en 1880, aparece con el Colón ese espacio de ilusión y de juego, donde la coalición se pone en escena, entre las mujeres, para reproducir 'en ficción' la escena del estado liberal" (LUDMER. El cuerpo del delito. Un manual, p. 48).

${ }^{52}$ LUDMER. El cuerpo del delito. Un manual, p. 87.

${ }^{53}$ LUDMER. El cuerpo del delito. Un manual, p. 88.
} 
presentado en términos didácticos; en su comportamiento político, el vínculo con el caudillo bonaerense Adolfo Alsina parece reproducir la relación del sargento Cabral entregando su vida por el general San Martín en la batalla de San Lorenzo: ambos responden ciegamente al jefe e instalan en la mitología y la literatura argentinas la ética del subordinado. Y Moreira, a su vez, anticipa una literatura violenta que ya había sido anunciada en la gauchesca: la de Osvaldo Lamborghini, en especial el relato "El fiord" que trasunta la crueldad de la política local, mencionada en el populismo peronista a partir de esa figura lateral de la cultura masiva que es Juan José de Soiza Reilly. El cuerpo del delito es un cuerpo previsto para el exterminio, no sin antes sufrir maltrato y tortura; es el corpus de una operación crítica que desafía los textos y que acaso lamenta los tonos canónicos de la patria, proliferantes en lecturas previsibles y tranquilizadoras.

Resumo: O presente trabalho estuda a carreira de Beatriz Sarlo e Josefina Ludmer, as duas mulheres mais representativas da crítica literária na Argentina das três últimas décadas do século XX. No caso de Sarlo, sua tarefa tem como foco o rastreamento de questões sociopolíticas nos textos, mudando de direção progressivamente para os estudos culturais nos anos 1990. Ludmer, ao contrário, começou com uma perspectiva estruturalista que se foi modificando embora sempre privilegiando os aspectos imanentes e as significações múltiplas dos textos. Ambas preferiram a crítica da literatura argentina, fornecendo um modelo de incorporações teóricas e perspectivas críticas, além de duas figuras contrapostas no que diz respeito à intervenção política da crítica. 


\section{REFERÊNCIAS}

ALTAMIRANO, C.; SARLO, B. Una vida ejemplar: la estrategia de Recuerdos de Provincia. In: Ensayos argentinos. De Sarmiento a la vanguardia. Buenos Aires: CEAL, 1983.

GRAMSCI, A. Los intelectuales y la organización de la cultura. México: Juan Pablos, 1984. (Cuadernos de la Cárcel 2)

LUDMER, J. Onetti, los proceso de construcción del relato. Buenos Aires: Sudamericana, 1977.

LUDMER, J. El género gauchesco. Un tratado sobre la patria. Buenos Aires: Sudamericana, 1988.

LUDMER, J. El cuerpo del delito. Un manual. Buenos Aires: Perfil, 1999.

RAMA, Á. Los gauchipolíticos rioplatenses. Montevideo: Arca, 1976.

SAID, E. W. Begginings. Intention and Method. New York: Columbia University Press, 1975.

SARLO, B. Una modernidad periférica. Buenos Aires 1920 y 1930. Buenos Aires: Nueva Visión, 1988.

SARLO, B. Jorge Luis Borges, a writer on the edge. London: Verso, 1993.

SARLO, B. Escenas de la vida posmoderna. Buenos Aires: Ariel, 1994.

SARLO, B. Borges, un escritor en las orillas. Buenos Aires: Ariel, 1995.

SARLO, B. La máquina cultural. Maestras, traductores y vanguardistas. Buenos Aires: Ariel, 1998.

WHITE, H. Metahistoria. México: Fondo de Cultura Económica, 1992. 